\title{
Development and Application of Integrated Services in Metropolitan Area Transmission Network
}

\author{
Lifen Wang and Mingtao Ma \\ Jilin Agricultural Science And Technology College, Jilin 132000, Jilin, China \\ mmt800@126.com
}

Keywords: Multi-Service Metropolitan transmission network; Multi-Service Transport Platform; packet transport network

\begin{abstract}
With the high-speed development of contemporary communication industry, Metropolitan networks is required to be a multi-Service platform for transmission. This article introduces the application of two key technologies, PTN and MSTP from the point of application, and the development process and construction program of it's metropolitan transmission network with the example of a prefecture.
\end{abstract}

\section{Introduction}

In recent years, with the growing demand for IP data, NGN, rental and other large customers demand service delivery, metro transport network need to own the diversity of business types and access environment and the changes in the demand for services, broadband access rate and other characteristics. Original metro transport network, whose primary purpose is carrying voice, has been unable to meet the requirements of multi-service transmission in terms of volume and interface capabilities, How to achieve rapid growth in IP services and traditional TDM transmission is the main problem which metro transport network faced in recent years. More mainstream solution is MSTP (multi-Service transport platform) technology, along with increased IP-based network, PTN (packet Transport Network) technology has become the direction of evolution MSTP network. The targt position of MSTP is shown in picture ${ }^{[1]}$.

\section{The Main Technology Of Multi-Service Metropolitan Transmission Network}

Comparison of MSTP Technology and the Use of Technical Equipment PTN Technology. MSTP device is based on the cross as the core SDH circuit device, just adding some data services, and can achieve transparent transmission of data services as well as some simple business gathering. The mapping of Ethernet, ATM and other services to the VC channel, transmite through the VC crossconnect matrix in SDH networks, which is applicable to a large number of traditional TDM , and a small number of IP cases ${ }^{[2]}$.

PTN equipment is at the core of the transmission packet switching equipment to Alcatel- Lucent 's TSS1850 for example, which uses general matrix , exchange and business process separation designed to allow a single platform to provide a smooth upgrade from traditional TDM circuit transmission equipment in order to provide point to point / multi-point ethernet transmission or aggregation, carrier Ethernet exchange services platform, and is fully inherited the advantages of high SDH network survivability, high quality service delivery ; open architecture. The use of network management system can be flexibly configured to any proportion of carrier-class Ethernet services, WDM and TDM switching services to meet the growing traffic demand. Applicable to a large number of IP services, the situation is a small traditional TDM services, due to its high degree of flexibility also applies to a large number of IP services in the early development ${ }^{[3]}$.

MSTP Technology and Device Applications Using PTN Technology. MSTP application types include the following: the new district and modules Bureau , using the FE MSTP pass-through 
interconnect DSLAM and aggregation to BRAS, and AG access equipment to NGN IP bearer network router interoperability even ; tobacco, public security and other large customers rent an Ethernet line, using the MSTP VLAN aggregation interconnect segments to headquarters ${ }^{[4]}$.

PTN is similer to MSTP in the existing network and application -level network, for future analysis , there are fixed and wireless business applications.

In the fixed service applications, PTN products are mainly used to complete the DSLAM, OLT fiber access network to send data network convergence and NGN access network to transmit SS AG, lease enterprise-class line access .

In the wireless business applications, PTN products are mainly used in access and aggregation layers. Primarily used to complete the $2 \mathrm{G} / 3 \mathrm{G}$ access traditional E1 and IP data services .

\section{Development of a PREFECTURE-Level City Metro Transport Network}

Development of a Prefecture-Level City Metro Transport Network. Take the metro transport network of a prefecture as an example ( hereinafter referred to as $\mathbf{J}$ City ), describes the development process of its metropolitan area. Optical transmission network of J City initially established using the point- and -chain equipment PDH networks . With sophisticated commercial and TDM voice -driven surge in demand self-healing and high-capacity SDH transmission ring network has been formed. In recent years they have MSTP function evolution to multi-service transport platform, and gradually replace the large number of MSTP equipment PDH game point, making the entire network with a powerful OAM ( operations management and maintenance ) the ability to achieve centralized control, multi-service access network resources and flexible scheduling ${ }^{[5]}$.

J City of SDH transmission network was founded in 1995, using NEC equipment to set up NEC2.5G MAN ( including a 2.5G four-fiber multiplex section shared protection ring and two 622M Multiplex Section Shared Protection Ring ), using traditional NEC SMS-2500A and SMS-600V SDH equipment, mainly carrying voice, DDN and rental 2M traditional TDM services .

Transmission network as a bearer network service network, provides transmission services for the business network, so the network design ideas should be based on the needs of the business network, a reasonable allocation of transmission resources. NEC 2.5G MAN's forming is mainly to meet the business needs of TDM switching, bearing each end office to tandem switching, end office to exchange trunk circuit between the end of the Council, the transmission network will also provide a convergence between the respective nodes transmission paths between nodes and backbone nodes between aggregation and backbone nodes .

Since PHS started the business, 10G metro transport network was set up in late 2001( including a two- 10G fiber SNCP ring, two 2.5G two-fiber multiplex section shared protection ring ). Aggregation nodes with the same inning $2.5 \mathrm{G}$ points backbone nodes connected using MSP1 +1 way, for a few years the business needs to be constantly expansion. So far $2.5 \mathrm{G}$ multiplex section protection ring has reached three, using Alcatel OMSN (Optical Multi-Service Node) series 1670SM (10G), 1660SM (2.5G) and 1650SMC (155/622M) transmission equipment, which can be upgraded with the MSTP feature, is currently only used for SDH traditional TDM bearer. As shown in Figure 2 Alcatel MAN status quo . 


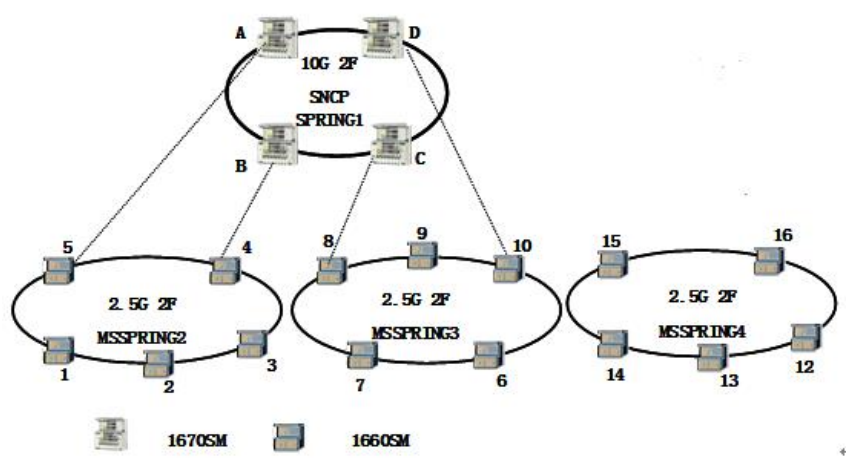

Figure 1. Alcatel MAN status quo

Alcatel 10G MAN formation is mainly to meet the needs of the PHS business, carrying each base station controller to $2 \mathrm{M}$ circuit of PHS . The transmission network will also provide a corresponding convergence between nodes and backbone nodes and backbone transmission path between nodes , because their business network hierarchy, basically there're no business requirements for gathering nodes, thus MAN Alcatel 10G aggregation does not provide the transmission path between nodes . Service scheduling rare convergence between nodes can be completed through a circuit jumper. After the formation of the network, re- allocation and optimization of the network time slots to meet the business needs of the later switched network intelligence reform and other projects .

From 2001 phasing out Huawei SDH transmission equipment for the original PDH equipment, using point to point or star networking, the highest rate is $622 \mathrm{M}$. In recent years, the rapid development of NGN applications and large customers leased circuits softswitch technologies, Huawei has also experienced a number of transmission network expansion optimization, setting up a new schedule for the completion of the convergence of business $2.5 \mathrm{G}$ backbone ring network, which has formed a MSTP of metro transport network, including six $2.5 \mathrm{G}$ ring, the rest of the ring is $622 \mathrm{M} / 155 \mathrm{M} 622 \mathrm{M}$ branched. According to changing business needs, flexible configuration transmission path to meet the business development.

Construction of a Prefecture-Level City Metro Transport Network. As present,J City metro transport network type of business is divided into the following categories, traditional TDM 2M electrical port , 155M optical port and MSTP supports Ethernet services[6] . 2M electrical interface mainly to meet the business needs of voice, DDN, ATM, customers leased circuits, and new base station ; 155M optical port interfaces to meet business needs of major exchange bureau , independent exchange bureau, ATM network ; Ethernet services mainly to meet the NGN network in the Union AG , a lack of fiber Bureau remote DSLAM business needs, such as the Alliance, large customers rent Ethernet services aspects. In recent years, the demand on the Union AG and Ethernet services major clients hire the increasing demand for bandwidth dedicated large customers also have the original $2 \mathrm{M}$ up to $34 \mathrm{M}$, or $155 \mathrm{M}$. This also means that gradually evolved into a metro transport network extends NGN bearer network data and virtual private network large customers, which is playing the role of integrated access platform.

On the construction, it can be considered fully MSTP of existing SDH network, and using PTN equipment in the core game point. According to the ratio of the actual business needs, PTN equipment can be temporarily used as MSTP equipment, and gradually to the packet-oriented business PTN equipment evolution. At the beginning of the construction, the use of dual-plane backbone layer (TDM 10 Gbit / s backbone layer, PTN backbone layer ) can exist as a business -sharing networks , and gradually consider integration and interoperability .

The main business requirements analysis : as a result of telecom operators restructuring,the three operators have become integrated wireless and fixed-line operators, faced with the $2 \mathrm{G}$ network expansion, the situation is about to start $3 \mathrm{G}$ services, metro transport network for $3 \mathrm{G}$ business has been 
a substantial increase in demand, the new 10G backbone MAN is imminent. Business growth comes mainly from $\mathrm{G}$ network expansion, expanding NGN networks . Due to the construction of the transmission network which have a certain forward-looking, network capacity should also take into account the demand for $3 \mathrm{G}$ services .

The following integrated services building in the evolution of MAN concrete building programs.

General requirements for network construction :establish a clear hierarchy backbone network service access layer flexible scheduling, convergence layer, metro transport network access layer three-lier structure . Since NEC equipment is too old, which does not have MSTP functions and network management system is out of date, unable to meet current business needs, its business cutover to MAN Alcatel and Huawei, NEC MAN on longer exits on the stage of history of Jilin City.

Thus J City metropolitan area has formed the pattern of the two networks Alcatel and Huawei coexist, network segmentation takes a vertical split mode, to avoid the transmission equipment from different manufacturers to bring interoperable networking problems and failures of the Selection Committee, conducive to network management and routine maintenance. In the future through progressive network to reach each node dual transmission backbone aggregation network coverage , enabling different business distributed networks, improve the transmission bearer network security and reliability .

In an example of this with Alcatel MAN detailed construction of the new network, the new Alcatel$10 \mathrm{G}$ ring network backbone network conditions after the transformation shown in Figure 2 .

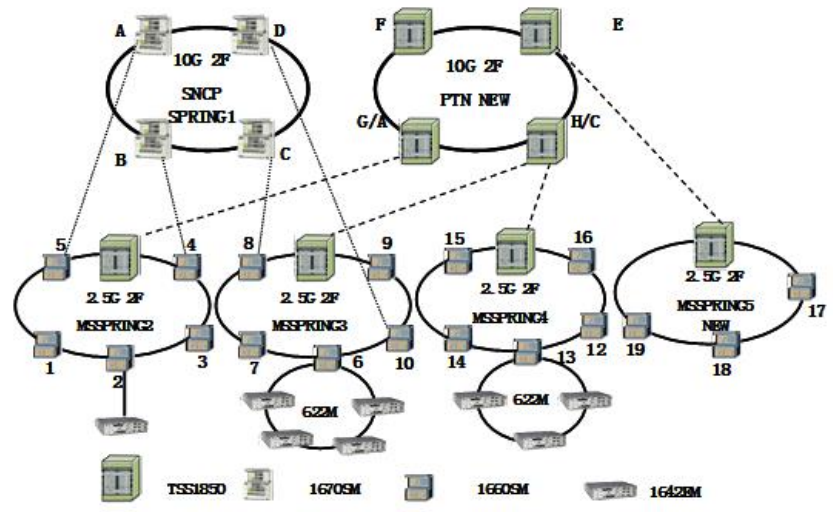

Figure 2. Alcatel- 10G ring network after transformation

Specific Programs are As Follows : Three-lier network architecture : 10G backbone ring network connecting the original fixed-line operators and wireless carriers backbone nodes, aggregation layer form 2.5G ring network, cable access layer should be based on resources, using ring or chain networking, with the rate of $622 \mathrm{M}$.

Original network and the new network convergence : the original three $2.5 \mathrm{G}$ ring were upgraded to own MSTP functions, and add a backbone nodes to each 2.5G ring, which achieve the new 10G ring network tangent, not only complete the exchange of new and old ring ring network, but also saves the original $2.5 \mathrm{G}$ slot resource aggregation nodes.

Equipment Selection : 10G backbone nodes using PTN equipment Alcatel-Lucent 's TSS1850-320 series making preparations for MSTP Network to evelute to the PYN network. Because the demand for TDM business service is greater than the current IP network, now TSS1850 equipment temporarily has the function for MSTP , along with the process of IP network, the need for further reform optimized MAN gradually evolved into being really smooth PTN network. AG, switching module, the service access layer of mobile base stations have passed OMSN series 1642EM155/622 MSTP equipment access convergence layer, convergence layer still use OMSN series 1660SM MSTP equipment[7].

So far Alcatel MAN completed from the traditional SDH tjo MSTP and gradually to the PTN network evolution . 


\section{Conclusion}

Grouping is an inevitable development in the direction of optical transport networks. Metropolitan area still faces a variety of issues such as business coexist for a long time, carrying particles diverse business. The metro transport network will be progressively developed,evoluted and optimizated, with the need of business development, to become a truly integrated service delivery platform, efficient, stable, secure, and reliable network to provide hosting services to businesses[8] .

\section{References}

[1] Fan Zhiwen, the MSTP architecture of service oriented. Fenghuo Communication Science \& technology, 2004. 10

[2] Wang Haiqing. MSTP technology in MAN applications. Computer and Information Technology .2007.24

[3] Zhang Hongbin. PTN applications and explore. Telecommunication Sciences, 2008.6

[4] Du Weijun; MSTP metropolitan area network solutions [J]; electronic technology; 2003, 23

[5] Deng Niu Chun Ping Xu. Existing MSTP SDH network transformation. Telecommunications engineering technology and standardization, 2008.1

[6] Wang Haizhou; [D] MSTP equipment 1000Mbps Ethernet aggregation card; Shanghai Jiao Tong University; 2006

[7] Liu Xiheng, the relationship between MSTP technology and network of data services, Huawei technical report 178th, 2003.05

[8] Wei Leping. Optical network technology development and prospect of Telecommunications Science, 2008.3 